\title{
Farklı açlık tokluk besleme döngülerinin lepistes (Poecilia reticulata) balıklarında cinsiyete göre büyüme performansı ve maliyet üzerine etkileri
}

\section{Effects of cycled starvation feeding regimes and gender on growth performance and cost analysis of guppy (Poecilia reticulata)}

\author{
Gürel Türkmen ${ }^{1} \bullet$ Onur Karadal ${ }^{* *}$ \\ ${ }^{1}$ Ege Üniversitesi, Su Ürünleri Fakültesi, Yetiştiricilik Bölümü, 35100, Bornova, İzmir, Türkiye \\ 2 İzmir Kâtip Çelebi Üniversitesi, Su Ürünleri Fakültesi, Yetiştiricilik Bölümü, 35620, Çiğli, İzmir, Türkiye \\ *Corresponding author. onur.karadal@ikc.edu.tr
}

How to cite this paper:

Türkmen, G. \& Karadal, O. (2017). Effects of cycled starvation feeding regimes and gender on growth performance and cost analysis of guppy (Poecilia reticulata). Ege Journal of Fisheries and Aquatic Sciences, 34(4):423-430. doi: 10.12714/egejfas.2017.34.4.09

\begin{abstract}
Öz: Lepistes (Poecilia reticulata), pratikte çoğu zaman düzenli beslemenin uygulanmadığı hatta çoğu günler beslemenin bile yapılmadığı görülen bir süs balığı türüdür. Bu çalışmada, farklı açılık tokluk beslenme döngülerinin lepistes balıklarında cinsiyete göre büyüme ve gelişme üzerine etkileri araştırımışıı. Çalışma dişi ve erkek bireylerde 3 tekrarlı olarak yürütülmüştür. Başlangıçta ortalama ağırlıkları ve total boyları $0,129 \pm 0,025 \mathrm{~g}$ ve 2,39 $\pm 0,20 \mathrm{~cm}$ olan dişi ve $0,122 \pm 0,019$ ve $2,39 \pm 0,14 \mathrm{~cm}$ olan erkek bireyler 30/50L stok yoğunluğunda kullanılmış̧ır. Denemede dişi (D) ve erkekler (E) ile ayrı deneme grupları oluşturularak, bu gruplar günde bir (K), bir gün aç bir gün tok (AT) ve iki gün aç bir gün tok (AAT) olarak beslenmişlerdir. Besleme doyana kadar pul yem ile yapıımıştır. Balıklarda büyüme ve gelişim 15 günde bir örnekleme (ağırlık ve total boy) ile 16 hafta boyunca takip edilmiştir. Çalışma sonunda en iyi ağırlık artışı dişi kontrol (KD) grubunda görülürken ATD grubu dişi bireylerde daha az ve AATD, KE, ATE ve AATE gruplarında ise eşit ağırlık arış̧ları görülmüştür $(P<0,05)$. Total boylar arasında anlamlı bir fark görülmese de $(P>0,05)$ en iyi total boy artışı KD ve KE gruplarında görülmüştür, diğer grupların total boy değerleri birbirlerine yakındır. Maliyet analizleri sonucunda ise en karlı besleme KD grubunda saptanmıştı. Sonuç olarak lepisteslerin ticari besiciliğinde en azından günde bir kez beslenmeleri önerilmiştir.
\end{abstract}

Anahtar kelimeler: Lepistes, Poecilia reticulata, besleme döngüsü, büyüme performansı, maliyet analizi

Abstract: Guppy (Poecilia reticulata) is an ornamental fish species which regular feeding has often been applied even it cannot be done on most days for its feeding, in practice. In this study, effects of cycled starvation feeding regimes and gender on growth of guppy were investigated. The study was carried out with three replicates with male and female groups. Female guppies with mean weight of $0.129 \pm 0.025 \mathrm{~g}$ and mean total lenght of $2.39 \pm 0.20 \mathrm{~cm}$ and male guppies with mean weight of $0.122 \pm 0.019 \mathrm{~g}$ and mean total lenght of $2.39 \pm 0.14 \mathrm{~cm}$ were placed to each aquarium with $30 \mathrm{ind} . / 50 \mathrm{~L}$ stocking density. In the experiment, female (D) and male (E) guppies were formed in separate groups, these groups were fed with once a day (K), every other day (AT) and other two days (AAT) starvation cycles. Fish were fed at satiation with flake feeds. Growth and development of fish were measured at every 15 days (weight and total lenght) during 16 weeks. The best weight gain was shown in female control group (KD) while lower in ATD than the KD group and equal weight gain was observed in the AATD, KE, ATE and AATE groups $(P<0.05)$. A significant difference was not appeared between mean total lenghts $(P>0.05)$. The best total lenght gain was shown in $K D$ and $K E$ groups, and also mean total length values of other groups are close to each other. As a result of cost analysis, the most profitable feeding has been stated on KD group. In conclusion, at least once a day feeding is recommended for commercial guppy feeding.

Keywords: Guppy, Poecilia reticulata, feeding cycle, growth performance, cost analysis

\section{GíRiş}

Süs balığı üretimi dünya genelinde yükselen bir ivmeye sahiptir. FAO verilerine göre 2011 yılında akvaryum sektöründeki toplam üretimin 717 milyon \$ olduğu belirtilmiştir (FAO, 2017). Yine son 10 yılda toplam üretim değerinde ciddi bir artış görülmektedir. Canlı balık ticareti haricinde diğer yan ürünler ile birlikte dünya akvaryum sektörünün $15-30$ milyar $\$$ seviyelerinde bir hacme ulaştığı belirtilmektedir (Çelik vd., 2014). Dünya süs balığı üretiminde meydana gelen artışa paralel olarak akvaryum sektöründe de hızlı gelişim ve değişim devam etmektedir. Modern kuluçkahane ve üretimhanelerde gerek cama cam akvaryumlarda gerekse daha gelişmiş kapalı devre sistemlerde akvaryum balığı yetiştiriciliği yapıımaktadır. Bu gelişmelerin sonucu olarak akvaryum sektöründe ele alınan tatlı su balıklarının yaklaşık \%90'ı yetiştiricilik yolu ile sağlanmaktadır (Türkmen vd., 2011). Süs balıkları yetiştiriciliğindeki bu gelişmeler akvaryum sektöründe ele alınma potansiyeli olan birçok tür ile yapılan çalışmaların da artmasına sebep olmuştur. Süs balıklarının önemli grupları arasında canlı doğuranlar, çiklitler, labirentliler ve sazangiller bulunmaktadır (Hill ve Yanong, 2010; Karadal ve Güroy, 2015). 
Çalışmada ele alınan lepistesler Poeciliidae familyasında bulunan, orijinleri Güney Amerika olan ve canlı doğuranlar grubuna ait türlerdir. Genellikle omnivor olarak beslenirler. Erkekleri renkli, dişileri ise sade olduğundan dolayı cinsiyet ayrımı kolay yapılmakta ve oldukça fazla sayıda yavru vermektedirler. Bu gibi özelliklerinden dolayı lepistes balıkları amatör akvaristler tarafından sıkça tercih edilmektedirler. Bu ilginin sonucu olarak lepistesler, pazar talebi en yüksek akvaryum balığı türleri arasındadır (Türkmen ve Alpbaz, 2001).

Sürdürülebilir ve ekonomik bir su ürünleri yetiştiriciliğinin, birçok faktörün kontrol altına alınması ile sağlanabilineceği düşünülmektedir. Balıklarda sağlıklı ve normal bir gelişim kaliteli bir yem rasyonu ve ideal bir besleme stratejisi ile gerçekleştirilebilir (Karadal vd., 2017). Dolayısıyla işletmelerde basit bir yemlemeden ziyade, üreticilerin kendi tecrübeleri ve kayıtları doğrultusunda belirledikleri metotlarla sistematik bir yemleme yönetimi uygulanması gereklidir. Yemlemedek başarı, yemlemeyi yapan personelin deneyimi ile de doğru orantılıdır. Bu kişinin balık davranışını ve balığın yem alımındaki iştahını iyi takip etmesi gerekir (Yiğit ve Çelikkol, 2011). Balıklar aşırı yemlendiği takdirde hem ekonomik hem de çevresel sorunlar meydana gelir (Talbot vd., 1999). Dolayısıyla sürdürülebilir yetiştiricilikten uzaklaşılmış olur. Balıklar az yemlendiğinde ise kanibalizm ve agresiflik gibi balıkların sağlığını olumsuz etkileyen stres faktörleri ortaya çıkmaktadır (Woynarovich vd., 2011). Diğer hayvanlarda olduğu gibi balıklarda da mide, açlık tokluk oranının belirlendiği en önemli organdır. Dolayısıyla midenin doluluğu tüketilecek yemin miktarını belirlemektedir. Balıkların midelerini boşaltmaları için gerekli zaman; su sıcaklığı, balık büyüklüğü, midenin yüzey alanı, tüketilen yemin yüzey alanına, yem miktarı ve kalitesi ile değişmektedir. Bu sebeple bir türün besleme stratejisinin belirlenmesi oldukça önemlidir (Okorie vd., 2013).

Telafi büyümesi veya açlık tokluk döngüsü, yetersiz yemleme dönemi / dönemlerinin ardından doymuş yemleme dönemi izlenerek gerçekleştirilen bir besleme rejimidir. Böylece, beslenme zamanları dikkatli bir şekilde seçilerek balıkların özellikle büyüme performanslarında iyileştirilmeler hedeflenir (Zhu vd., 2004). Sınırlı yemlemeyi takiben yapılan iyileşme döneminde elde edilen ağırlık kazancı ne kadar fazlaysa, besleme rejimi o kadar başarılıdır denilebilir (Kim ve Lovell, 1995). Lepisteslerin ticari üretimlerinde günde 3-5 kez besleme programı uygulanmasına karşın hobi amaçlı bakımlarında günde bir kez beslenmeleri önerilmektedir. Pratikte ise çoğu zaman düzenli beslemenin uygulanmadığ hatta çoğu günler beslemenin yapılamadığı görülmektedir (Harpaz vd., 2005). Dolayısıyla, bu gelişigüzel besleme alışkanlığından pozitif çıktılar elde edebilmek için telafi büyümesi uygulanabileceği düşünülmektedir. Ayrıca, birçok balık türü ile telafi büyümesi ya da döngülü açlık tokluk besleme çalışmalarının yapılmış olmasına karşın lepistes türü üzerine benzer çalışmaların yeterince yapılmadığı görülmüştür.

Bu çalışmanın amacı, akvaryum sektöründe yaygın olan lepistes balıklarında farklı açlık tokluk döngüleri (her gün, bir gün aç bir gün tok ve iki gün aç bir gün tok) uygulanarak yemleme isteminin sınırlandırılması ve uygulanacak rejim açısından en uygun maliyetin araştırımasıdır. Ayrıca büyüme performansı ve maliyet parametrelerinin cinsiyet farklılıkları ön plana alınarak değerlendirmesi de yapıımıştır.

\section{MATERYAL VE METOT}

\section{Deneme balıkları}

Çalışmada özel bir işletmeden temin edilen Poecilia reticulata türü lepisteslerin Alman varyetesi kullanılmıştır. Çalışma başlangıcında ortalama ağırlıkları ve total boyları $0,129 \pm 0,025 \mathrm{~g}$ ve $2,39 \pm 0,20 \mathrm{~cm}$ olan dişi ve $0,122 \pm 0,019 \mathrm{~g}$ ve $2,39 \pm 0,14 \mathrm{~cm}$ olan erkek bireyler 16 hafta boyunca farklı açlık tokluk rejimlerinde beslenerek büyüme, gelişme ve yaşama oranları araştırılmıştır. Lepistesleri beslemede TetraMin $®$ marka pul yem kullanıımıştır (Tablo 1).

Tablo 1. Deneme yeminin kimyasal kompozisyonu

Table 1. Chemical composition of experimental diet

\begin{tabular}{ll}
\hline İçerik & Pul Yem \\
\hline Ham Protein (\%) & 46 \\
Ham Yağ (\%) & 8 \\
Ham Selüloz (\%) & 2 \\
Ham Kül (\%) & 10 \\
Nem (\%) & 6 \\
\hline
\end{tabular}

\section{Deneme dizaynı}

Deneme, Ege Üniversitesi Su Ürünleri Fakültesi'nde yürütülmüştür. Denemede dişi (D) ve erkekler (E) ile ayrı deneme grupları oluşturularak, bu gruplar günde bir $(K)$, iki günde bir (AT) ve üç günde bir (AAT) beslenmişlerdir (Şekil 1). Tüketilmeyen yemler ortamdan sifon yardımı ile alınmıştır. Çalışmada $47 \times 31 \times 34 \mathrm{~cm}$ boyutlarında cam akvaryumlar kullanılmıştır. Her bir akvaryuma 30 adet birey konulmuştur. Deneme 3 tekrar ile 18 akvaryumda yürütülmüştür (Şekil 1). Su sıcaklığı $25,7 \pm 0,3 \quad{ }^{\circ} \mathrm{C}$ ve fotoperiyot $14: 10$ saat (aydınlık:karanlık) şeklinde uygulanmıştır. Akvaryumlarda haftada $2 \mathrm{kez} \% 30$ oranında su değişimi yapıımıştır. Su değişiminden sonra tüm akvaryumlara sürekli havalandırılan klorsuz musluk suyu ilave edilmiştir. Her akvaryumdaki çözünmüş oksijen (WTW-Oxi 315), pH (Sartorius PT-10), amonyak (HANNA C205), su sertliği (Aquamerck® 114652 toplam sertlik test kiti) ve alkalilik (Aquamerck® 111109 alkalilik test kiti) değerleri deney başlangıcında, su değişimlerinde ve deney sonunda ölçülmüştür.

\section{Büyüme performansının belirlenmesi}

Büyüme performansı verileri, iki haftada bir yapılan ağırlık, total ve standart boy ölçümleri ile elde edilmiştir. Ağırlık ölçümleri deneme başlangıcı ve deneme sonunda bireysel olarak yapıımış, ara tartımlarda ise biyomas şeklinde alınmıştır. Tartımdan önce balıklar tanklardan kepçe ile toplandıktan sonra kağıt havlu ile kurutulmuştur. Yem tüketiminin 
belirlenebilmesi açısından ise her ara tartımın sonunda kalan yemler tartılmıştır. Ağırlık ölçümlerinde $0,1 \mathrm{mg}$ duyarlı analitik terazi (AND GR-200) kullanılmıştır. Total boy ölçümleri ise tüm balıklarda kumpas ile yapılmıştır. Ayrıca, denemeler süresince ölen balıklar tank numaralarına ve deneme gruplarına göre kaydedilerek deneme sonunda yaşama oranları tespit edilmiştir. Büyüme parametreleri aşağıdaki formüllere göre hesaplanmıştır.

Büyüme parametrelerinin hesaplanmasında;

- Ağırlık artışı = Son Ağırlık - İlk Ağırlık
- Yem Dönüşüm Oranı = Harcanan Yem Miktarı / Ağırlık Artışı - Spesifik Büyüme Oranı = [(In Son Ağırlık - In İlk Ağırlık) / Süre] x 100

- Kondisyon Faktörü = Son Ağırlık / (Son Standart Boy) ${ }^{3}$ x 100

- Yem Tüketimi = Verilen Toplam Yem Ağırlığı / Tanktaki Balık Sayısı

- Yaşama Oranı = (Canlı Balık - Ölen Balık) $/$ Toplam Balık x 100

formüllerinden yararlanılmıştır.

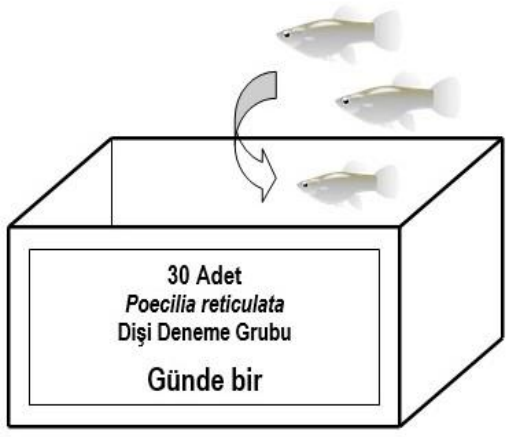

3 Tekrar

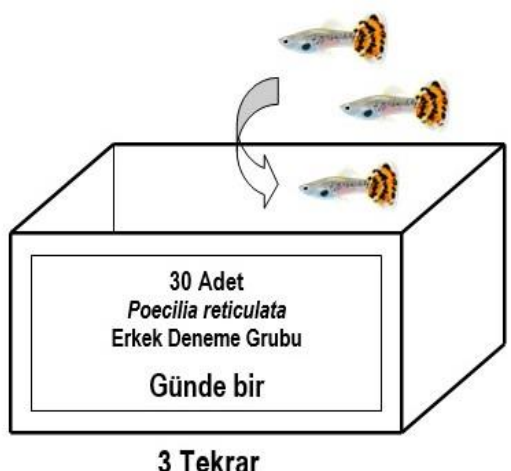

3 Tekrar

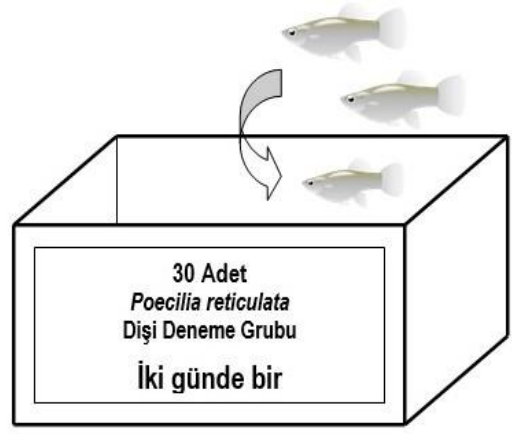

3 Tekrar

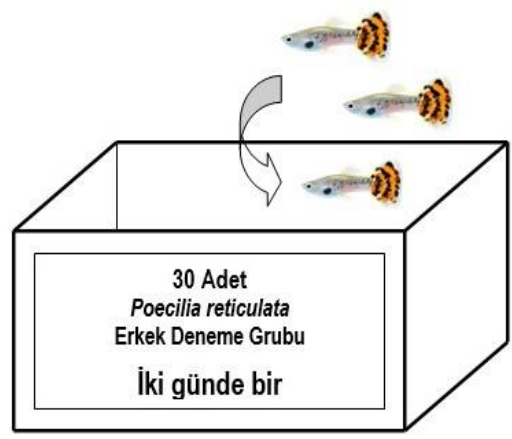

3 Tekrar

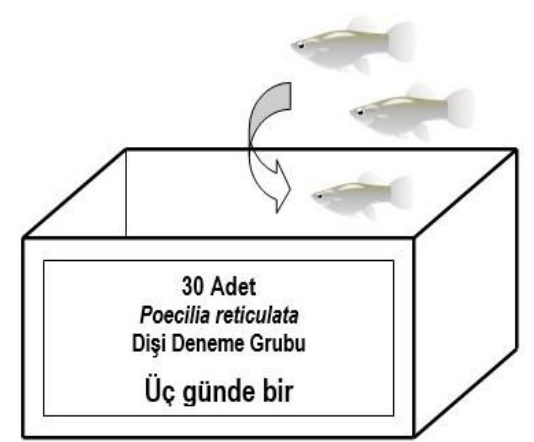

3 Tekrar

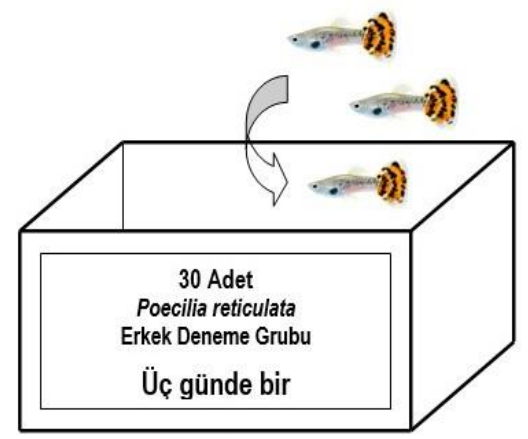

3 Tekrar

Şekil 1. Çalışma düzeneği

Figure 1. Schedule of experimental design

\section{Maliyet analizleri}

Çalışmada kullanılan yemler ile balıkların büyümesi arasındaki ilişkiyi ekonomik açıdan değerlendirmek amacıyla Martinez-Llorens vd. (2007)'e göre maliyet analizi yapılmıştır. Bu bağlamda, ekonomik dönüşüm oranı ve ekonomik karlılık indeksi aşağıdaki formüllere göre hesaplanmıştır:

- Ekonomik Dönüşüm Oranı = Yem Dönüşüm Oranı x Yem Maliyeti

- Ekonomik Karlıık İndeksi = [(Son Ağırlık x Satış Fiyatı) (EDO x Ağırlık Kazanımı)]

\section{İstatistiksel analizler}

Büyüme verilerinin istatistiksel olarak değerlendirilmesinde çift yönlü varyans analizi (ANOVA) uygulanmıştır. Gruplar arasındaki farkııı̆ın tespitinde ise Duncan testinden yararlanılmıştır. Verilerin bilgisayar ortamında istatistiksel değerlendirilmesi Statgraphics Centurion XVI paket programıyla sağlanmış ve grafikler MS Office Excel programıyla oluşturulmuştur (Zar, 2001). Elde edilen ortalama değerler "Ortalama \pm Standart Hata" şeklinde verilmiştir. Tüm testlerde yanılma düzeyi $P<0,05$ olarak kabul edilmiştir. 


\section{BULGULAR}

Denemedeki erkek ve dişi balıklara ait büyüme performansları Tablo 2'de verilmiştir. Deneme sonunda en yüksek ortalama ağırlık KD grubundan elde edilirken $(1,27 \mathrm{~g})$, AATD grubu ile KE, ATE ve AATE gruplarının ortalama ağırlıkları istatistiksel açıdan benzerdir $(P<0,05)$. Ayrıca son ortalama ağırlık değeri cinsiyet farklılığından etkilenmiştir $(P=0,0154)$. Ağırlık artışında son ortalama ağırlıktaki gibi benzer istatistiksel değişimler görünmesine rağmen hem açlık tokluk döngüsü hem de cinsiyet farkllliğından etkilendiğ sonucuna varıımıştır $(P=0,0353$ ve $P=0,0098)$. Balıkların son ortalama total boylarında herhangi bir istatistiksel farkllık ortaya çıkmamış olsa da $(P>0,05)$ yine en yüksek değer $K D$ grubunda $(4,77 \mathrm{~cm})$ tespit edilmiştir. Son ortalama standart boy verilerine göre, istatistiksel açıdan gruplar arasında en düşük ve en yüksek büyüme oranları sırasıyla AATE $(2,54 \mathrm{~cm})$ ve $K D$ $(3,77 \mathrm{~cm})$ gruplarında görülmüştür $(P<0,05)$. Bunun dışında grupların son ortalama standart boyları hem açlık tokluk döngüsü hem de cinsiyet farkılıı̆ından etkilenmiştir $(P=0,0113$ ve $P=0,0031)$. Grupların yaşama oranları yalnızca açlık tokluk döngüsünden etkilenmiş $(P=0,0002)$ ve $K$ gruplarında beslenenlerde en yüksek, AAT gruplarında ise en düşük değerler bulunmuştur $(P<0,05)$. KD ve ATD gruplarının spesifik büyüme oranları diğer gruplara nazaran daha yüksek olmakla birlikte bu gruplar arasında da istatistiksel farklılık ortaya çıkmıştır $(P<0,05)$. Bununla birlikte spesifik büyüme oranlarının açlık tokluk döngüsü ve cinsiyet farklıı̆ı yönlerinden de etkilendiği saptanmıştır $(P<0,05)$. ATE grubunda en yüksek yem dönüşüm oranı $(2,06)$ bulunurken, $\mathrm{KD}$ grubunda $(1,28)$ bu değer istatistiksel anlamda en düşük seviyededir $(P<0,05)$. Ayrıca yem dönüşüm oranının cinsiyet farklıı̆̆ından etkilendiği bulunmuştur $(P<0,05)$. Grupların yem tüketimi ve kondisyon faktörü parametreleri arasında herhangi bir istatistiksel farklıı̆ga rastlanmamıştır $(P>0,05)$.

Deneme süresince haftalık ağırlık değişimi Şekil 2'te verilmiştir. Her gün beslenen dişilerin (KD) ağırlıklarının 2 . haftadan itibaren diğer gruplara oranla daha yüksek bir ivmeyle arttığı görülmüştür. Total ve standart boyların deneme boyunca haftalık değişimleri sırasıyla Şekil 3 ve Şekil 4 'te sunulmuştur. Grupların total boyları arasındaki değişimlerin yakın seviyelerde oluşmasına rağmen standart boylarda yine 2 . haftadan itibaren daha fazla artış gözlenmiştir. Dişi deneme gruplarından alınan ortalama yavru sayılarının 2 haftalık değişimleri ise Şekil 5'te sunulmuştur.

Deneme sonundaki maliyet analizleri Tablo 3'te sunulmuştur. Bu analizlere göre, ekonomik dönüşümü en yüksek grup ATE grubu iken en düşük grup ise KD grubudur $(P>0,05)$. Karlılık açısından ise $K D$ grubu istatistiksel olarak, ATD grubu dışındaki diğer tüm gruplardan daha üstündür $(P<0,05)$. Maliyet analizlerindeki her iki parametre cinsiyet farklııklarından etkilenmiştir $(\mathrm{P}<0,05)$.

Çalış̧ma boyunca su kriterleri; çözünmüş oksijen $8,42 \pm 0,27$ $\mathrm{mg} / \mathrm{L}, \mathrm{pH}$ için $7,91 \pm 0,18$ amonyak için $0,05 \pm 0,02 \mathrm{mg} / \mathrm{L}$, nitrit için $0,02 \pm 0,01 \mathrm{mg} / \mathrm{L}$, alkalinite için $87,09 \pm 4,64 \mathrm{mg} / \mathrm{L}$, sertlik için $121,39 \pm 5,88 \mathrm{mg} / \mathrm{L}$ olarak kaydedilmiştir.

Tablo 2. Dişi ve erkek lepisteslerin 16 hafta sonundaki büyüme performansları

Table 2. Growth performance of female and male guppies after 16 weeks

\begin{tabular}{|c|c|c|c|c|c|c|c|c|c|}
\hline \multirow{2}{*}{ Parametreler } & \multicolumn{3}{|c|}{ Dişi } & \multicolumn{3}{|c|}{ Erkek } & \multicolumn{3}{|c|}{ Çift Yönlü ANOVA } \\
\hline & $\mathrm{K}$ & AT & AAT & $\mathrm{K}$ & AT & AAT & Döngü & Cinsiyet & Etkileşim \\
\hline İlk ortalama ağırlık & $0,13 \pm 0,03$ & $0,13 \pm 0,02$ & $0,13 \pm 0,03$ & $0,12 \pm 0,02$ & $0,13 \pm 0,02$ & $0,13 \pm 0,02$ & 0,9833 & 0,7606 & 0,9927 \\
\hline Son ortalama ağırlık & $1,27 \pm 0,32^{b}$ & $0,83 \pm 0,08^{a b}$ & $0,61 \pm 0,08^{a}$ & $0,63 \pm 0,12^{a}$ & $0,46 \pm 0,01^{a}$ & $0,40 \pm 0,05^{a}$ & 0,0582 & 0,0154 & 0,3968 \\
\hline Ağırlık artışı & $1,41 \pm 0,29 b$ & $0,70 \pm 0,05^{\mathrm{ab}}$ & $0,48 \pm 0,05^{a}$ & $0,51 \pm 0,10^{a}$ & $0,33 \pm 0,01^{a}$ & $0,28 \pm 0,03^{a}$ & 0,0353 & 0,0098 & 0,3218 \\
\hline İlk ortalama total boy & $2,39 \pm 0,20$ & $2,39 \pm 0,21$ & $2,41 \pm 0,21$ & $2,40 \pm 0,14$ & $2,39 \pm 0,20$ & $2,40 \pm 0,19$ & 0,9968 & 0,9918 & 0,9995 \\
\hline Son ortalama total boy & $4,77 \pm 0,34$ & $4,15 \pm 0,19$ & $4,14 \pm 0,22$ & $4,55 \pm 0,15$ & $4,18 \pm 0,13$ & $4,14 \pm 0,13$ & 0,0775 & 0,7238 & 0,8026 \\
\hline $\begin{array}{l}\text { İlk ortalama standart } \\
\text { boy }\end{array}$ & $1,98 \pm 0,17$ & $2,00 \pm 0,18$ & $2,02 \pm 0,18$ & $1,89 \pm 0,03$ & $1,88 \pm 0,05$ & $1,92 \pm 0,04$ & 0,9648 & 0,3492 & 0,9946 \\
\hline $\begin{array}{l}\text { Son ortalama standart } \\
\text { boy }\end{array}$ & $3,77 \pm 0,17^{d}$ & $3,29 \pm 0,15^{\mathrm{cd}}$ & $3,00 \pm 0,08^{a b c}$ & $3,09 \pm 0,24^{b c}$ & $2,70 \pm 0,07^{a b}$ & $2,54 \pm 0,13^{a}$ & 0,0113 & 0,0031 & 0,7710 \\
\hline Yaşama oranı (\%) & $91,67 \pm 1,67 c$ & $76,67 \pm 3,33^{b}$ & $61,67 \pm 1,67 a$ & $91,67 \pm 5,00^{c}$ & $80,00 \pm 3,33^{b}$ & $60,00 \pm 3,33^{a}$ & 0,0002 & 0,8417 & 0,7484 \\
\hline Spesifik büyüme oranı & $2,03 \pm 0,05^{e}$ & $1,66 \pm 0,08^{d}$ & $1,37 \pm 0,05^{b c}$ & $1,46 \pm 0,03^{c d}$ & $1,16 \pm 0,13^{\mathrm{ab}}$ & $1,04 \pm 0,05^{a}$ & 0,0009 & 0,0002 & 0,2967 \\
\hline Yem dönüşüm oranı & $1,28 \pm 0,12^{a}$ & $1,54 \pm 0,34 a b$ & $1,58 \pm 0,36 \mathrm{ab}$ & $1,88 \pm 0,15^{\mathrm{ab}}$ & $2,06 \pm 0,03^{b}$ & $2,00 \pm 0,01^{a b}$ & 0,5538 & 0,0281 & 0,9189 \\
\hline Yem tüketimi & $0,59 \pm 0,13$ & $0,53 \pm 0,03$ & $0,50 \pm 0,14$ & $0,46 \pm 0,14$ & $0,65 \pm 0,06$ & $0,55 \pm 0,05$ & 0,7605 & 0,8883 & 0,4692 \\
\hline Kondisyon faktörü & $2,31 \pm 0,28$ & $2,33 \pm 0,11$ & $2,24 \pm 0,12$ & $2,12 \pm 0,08$ & $2,33 \pm 0,07$ & $2,44 \pm 0,06$ & 0,6340 & 0,9646 & 0,4315 \\
\hline
\end{tabular}

${ }^{*} \mathrm{~K}$ : Kontrol (her gün), AT: Bir gün aç bir gün tok, AAT: İki gün aç bir gün tok

${ }^{*}$ Aynı satırdaki farklı harflerle gösterilen ortalamalar istatistiksel olarak farklıdır $(P<0,05)$ 


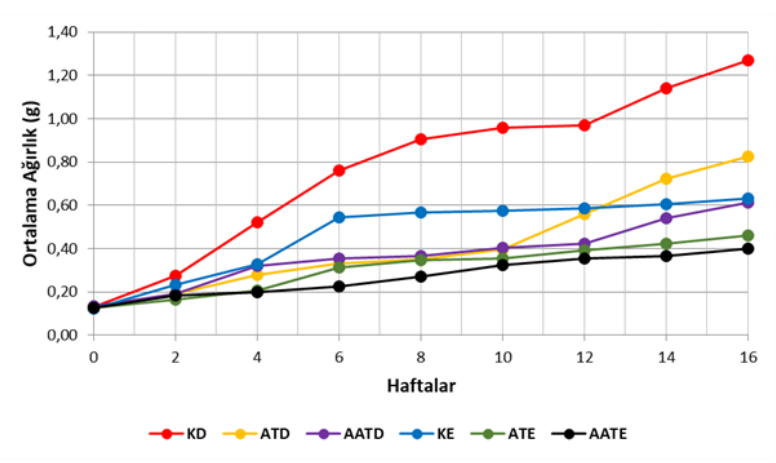

Şekil 2. Deneme gruplarının 16 hafta boyunca ortalama ağırlıkları Figure 2. Mean weights of experimental groups during 16 weeks

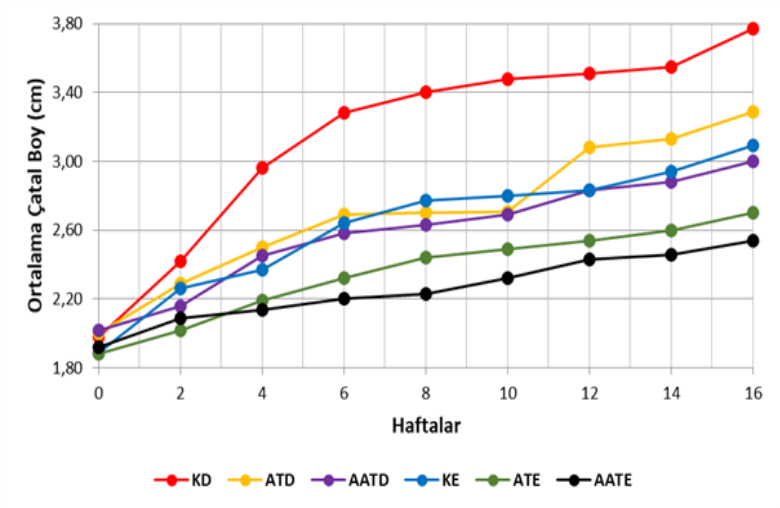

Şekil 4. Deneme gruplarının 16 hafta boyunca ortalama standart boyları

Figure 4. Mean fork lenghts of experimental groups during 16 weeks

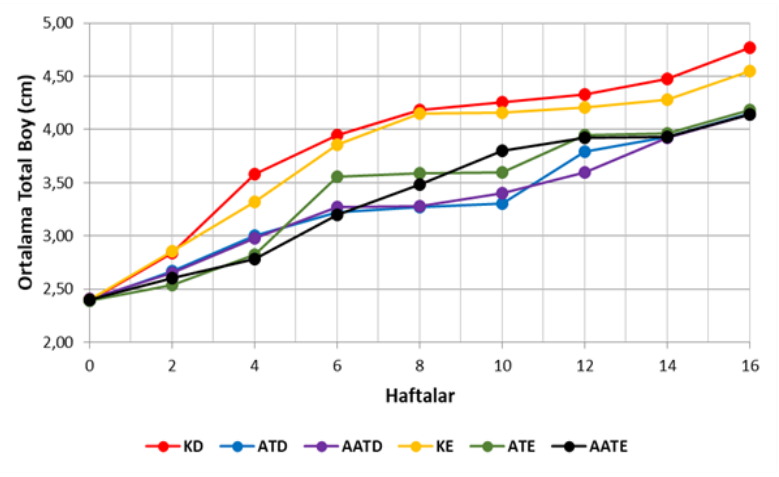

Şekil 3. Deneme gruplarının 16 hafta boyunca ortalama total boyları Figure 3. Mean total lenghts of experimental groups during 16 weeks

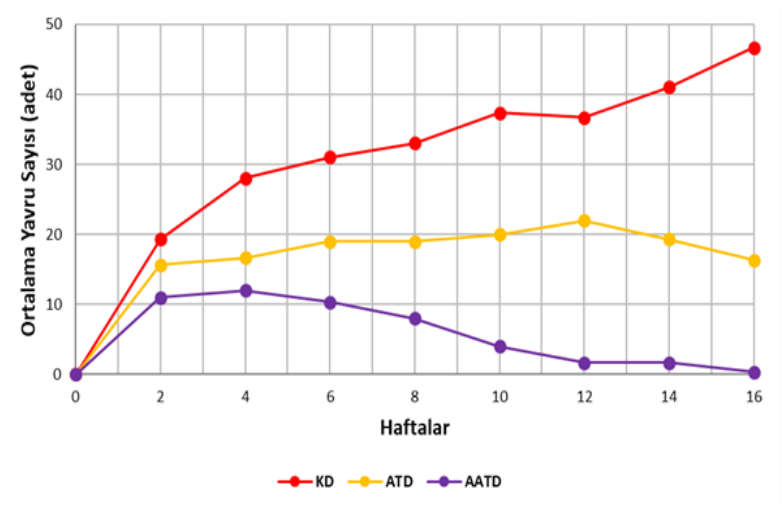

Şekil 5. Dişi deneme gruplarının 16 hafta boyunca ortalama yavru sayıları

Figure 5. Mean offspring counts of female experimental groups during 16 weeks

Tablo 3. Dişi ve erkek lepisteslerin 16 hafta sonundaki maliyet analizleri

Table 3. Economical analysis of female and male guppies after 16 weeks

\begin{tabular}{lccccccccc}
\hline \multirow{2}{*}{ Parametreler } & \multicolumn{3}{c}{ Dişi } & \multicolumn{3}{c}{ Erkek } & & \multicolumn{2}{c}{ Çift Yönlü ANOVA } \\
\cline { 2 - 10 } & \multicolumn{1}{c}{ K } & AT & AAT & K & AT & AAT & Döngü & Cinsiyet & Etkileşim \\
\hline Ekonomik dönüşüm oranı & $0,038 \pm 0,004^{\mathrm{a}}$ & $0,046 \pm 0,010^{\mathrm{ab}}$ & $0,047 \pm 0,011^{\mathrm{ab}}$ & $0,056 \pm 0,005^{\mathrm{ab}}$ & $0,062 \pm 0,001^{\mathrm{b}}$ & $0,060 \pm 0,001^{\mathrm{ab}}$ & 0,5538 & 0,0281 & 0,9189 \\
Ekonomik karlllik indeksi & $1,23 \pm 0,30^{\mathrm{b}}$ & $0,79 \pm 0,08^{\mathrm{ab}}$ & $0,59 \pm 0,07^{\mathrm{a}}$ & $0,60 \pm 0,12^{\mathrm{a}}$ & $0,44 \pm 0,01^{\mathrm{a}}$ & $0,38 \pm 0,05^{\mathrm{a}}$ & 0,0569 & 0,0145 & 0,3838 \\
\hline
\end{tabular}

${ }^{*} \mathrm{~K}$ : Kontrol (her gün), AT: Bir gün aç bir gün tok, AAT: İki gün aç bir gün tok

-Yemin kg fiyatı tüm deneme grupları için 30 も olarak alınmış ve $\mathrm{g}$ değeri kullanıımıştır.

-Lepistes türünün g fiyatı 1 も olarak alınmıştır.

${ }^{*}$ Aynı satırdaki farklı harflerle gösterilen ortalamalar istatistiksel olarak farkııır $(P<0,05)$

\section{TARTIŞMA VE SONUÇ}

Bu çalışmada, akvaryum sektöründe pazar talebi oldukça yüksek olan lepistes türü kullanılmış ve cinsiyete bağlı olarak farklı açlık tokluk döngüleri uygulanmıştır. Çalışma sonucunda en iyi ağıllık ve boy artışı her gün beslenen dişi lepisteslerde ortaya çıkmıştır. Çalışma bulgularına göre, erkek lepisteslerin her gün, iki günde bir ya da üç günde bir beslemesi istatistiksel anlamda herhangi bir önem taşımamaktadır. Ayrıca, her gün beslenen erkeklerin ancak üç günde bir beslenen dişiler kadar büyüyebildiği ortaya konulmuştur. Her gün beslenen dişilerin ise hem yavru verimi hem de karlıık açısından en yüksek değerlere sahip oldukları tespit edilmiştir. Dolayısıyla lepisteslerin, düzgün bir besleme rejimiyle çok kolay bir biçimde 
büyüdükleri ve üredikleri söylenebilir. Ayrıca lepistesler canlı doğuran balıklar oldukları için yavrular, su ortamında yumurta gibi hassas bir evrede bulunmazlar. Fakat ebeveynler aç kaldıkları zaman yavrular için predatör tehlikesi oluştururlar (Krause ve Liesenjohann, 2012). Düzenli bir besleme rejimi sağlandığı takdirde ise yavrularını yemezler ve böylece üreme verimliliğinde artış görülür.

Royle vd. (2006) lepisteslerle yaptıkları besleme döngüsü çalışmasında üç farkı deneme grubu oluşturmuşlardır. GG grubunu çalışma boyunca her gün, PG grubunu çalışmanın ilk yarısında haftada üç kez diğer yarısında her gün, PP grubunu ise çalışma boyunca haftada üç kez beslemişlerdir. PG grubundaki bireylerin, denemenin ilk yarısında PP grubu kadar yavaş büyüdüklerini, ancak her gün beslemeye geçildiğinde ise deneme sonunda boyut bakımından PG grubu erkeklerinin GG grubundaki erkekleri tamamen, PG dişilerinin ise GG dişilerini hemen hemen yakaladıkları bildirilmiştir. James ve Sampath (2003) $0,04 \mathrm{~g}$ ağılık ve $13,10 \mathrm{~mm}$ total boya sahip kılıçkuyruklarda (Xiphophorus helleri) üç günde bir, iki günde bir, günde bir, günde iki ve günde üç kez uygulanan besleme döngülerinin büyüme ve üreme performansı üzerine etkilerini araştırmışlardır. 210 gün süren çalışmanın sonucunda en yüksek büyüme günde üç kez beslenen grupta görülmüştür. Ayrıca, gonad ağırlığı ve gonadosomatik indeks gibi üreme parametrelerinin besleme ile doğru orantılı olarak arttığını belirtmişlerdir. Günde üç kez beslenen gruptan toplam 704 yavru elde edilirken, iki gün aç bir gün tok beslenen gruptan yalnızca 8 yavru alındığını bildirmişlerdir. Lepistes türü ile yürütülen bu çalışmada ise dişi ve erkek balıklar deneme süresince ayrı akvaryumlarda tutulmasına rağmen dişilerin yavru bıraktıkları görülmüştür. Başlangıçta aynı akvaryumda bulunan dişi ve erkek balıkların daha sonra deneme amaçlı ayrı akvaryumlara dağıtılmasıyla birlikte lepisteslerin sperm depolama özellikleri sayesinde yavru bıraktıkları düşünülmektedir. Aral ve Şahin (2015) dişi lepisteslerin 9 ay boyunca sperm depolayabildiklerini ve yavru bırakabildiklerini bildirmişlerdir. $\mathrm{Bu}$ denemede, $\mathrm{KD}$ grubundan ortalama $273,33 \pm 9,53$ adet, ATD grubundan 147,33 $\pm 11,05$ adet ve AATD grubundan ise $48,67 \pm 4,81$ adet yavru alınmıştır. Lepisteslerde açlık stresi hem yavru verimliliğini azaltan hem de kanibalizmi artıran önemli bir faktördür (Meffe ve Vrijenhoek, 1981). Auer vd. (2010) lepisteslerle yaptıkları çalışmada, telafi büyümesinin üreme performansına negatif etkileri olduğunu bildirmişler ve yavru üretiminin kontrol grubuna göre \%20 azaldığını ortaya koymuşlardır. Dolayısıyla bu denemenin çıktıları, canlı doğuran türleriyle yapılan önceki çalışmaların sonuçları ile uyumluluk göstermektedir.

Diğer akvaryum balıklarında besleme döngülerinin büyüme performansı üzerine etkilerini araştıran çeşitli çalışmalar yürütülmüştür. James ve Sampath (2004) $0,45 \mathrm{~g}$ ağırlık ve $14,43 \mathrm{~mm}$ total boya sahip beta (Betta splendens) balıklarını 77 gün boyunca iki gün aç bir gün tok, bir gün aç bir gün tok, her gün, günde iki kere ve günde üç kere beslemişlerdir. Bu türde günde iki kere beslemenin optimum olduğu sonucuna varmışlardır. Fujimoto vd. (2016) melek balıklarıyla
(Pterophyllum scalare) yaptıkları çalışmada, günde bir, günde iki ve günde dört kere olmak üzere kontrol gruplarını haftanın her günü, diğer grupları ise haftada üç defa ticari bir yem ile beslemişlerdir. Günde dört kere beslenen telafi büyümesi grubunun ancak günde iki kere beslenen kontrol grubu kadar büyüyebildiklerini bildirmişlerdir. Kasiri et al. (2011) aynı türün 0,87 g ağırlığa sahip bireyleri üzerine yürüttükleri çalışmada günde iki ve dört defa beslenen gruplarda ortalama son ağılıkların ve spesifik büyüme oranlarının diğer gruplara göre daha yüksek olduğunu belirtmişlerdir. En yüksek yem dönüşüm oranına sahip olan grubun günde dört defa beslenenler olduğu ve grupların yaşama oranları ile kondisyon faktörleri arasında herhangi bir istatistiksel farklılık olmadığı ortaya konulmuştur. Çalışmada en düşük büyüme performansının bir gün aç bir gün tok olarak beslenen grupta görüldüğü bildirmiştir. Bu çalışmaya benzer bir sonuç, Montajami et al. (2012) tarafından Teksas çiklitlerde (Herichthyes cyanoguttatus) yürütülen araştırmada rapor edilmiştir. Genel olarak diğer akvaryum türleriyle yapılan tüm bu çalışmalarda balıkların her gün beslenmesi gerektiği ve düzenli bir besleme olmadığı takdirde mortaliteye kadar uzanan olumsuz durumların ortaya çıktığı üzerinde durulmuştur.

Telafi büyümesi, özellikle akvaryum köpek balığı olarak bilinen pangasius türleri üzerinde de çalışılmıştır. Rohul Amin vd. (2005) Pangasius hypophthalmus türüyle yaptıkları çalışmada, 38,5 g ağırlığa sahip balıkları 18 hafta boyunca dört farklı rejimde beslenmişlerdir. A grubu her gün iki kez, B grubu bir gün aç bir gün tok, $C$ grubu iki gün aç iki gün tok ve $D$ grubu beş gün aç beş gün tok şeklinde deneme grupları oluşturulmuştur. Sonuçta balıkların son vücut ağırlıkları ve kondisyon faktörleri besleme azaldıkça düşerken spesifik büyüme oranlarında artış görüldüğü bildirilmiştir. Jiwyam (2010) ise $P$. bocourti türünde yem dönüşüm oranının açlıkla birlikte yükseldiği sonucuna varmıştır. Bu çalışmalarda telafi büyümesi ile beslenen balıklar kontrol grubunun büyüme performansını yakalayamamış ve sonuçları bizim bulgularımızla paralellik göstermiştir. Fakat yine çeşitli kedi balıkları türleriyle yapılan bazı çalışmalarda telafi büyümesinin olumlu etkilerinden söz edilmektedir. Zhu vd. (2004) Leiocassis longirostris türünde kontrol grubunu günde iki kez, telafi büyümesi grubunu bir hafta aç iki hafta tok şeklinde 12 hafta boyunca beslemişlerdir. Deneme sonunda büyüme performansı açısından telafi büyümesi grubunun kontrol grubunu $\% 75-80$ oranında yakaladığını belirtmişlerdir. Chatakondi ve Yant (2001) 2,5 g ağırlığa sahip kanal yayın balıklarını (Ictalurus punctatus) 10 hafta boyunca her gün, bir gün aç bir gün tok, iki gün aç bir gün tok ve üç gün aç bir gün tok şeklinde beslemişlerdir. Deneme bitiminde her gün beslenen balıklar $26 \mathrm{~g}$, dört günde bir beslenenler ise $30 \mathrm{~g}$ ağırlığa ulaşmışlardır. Bu çalışma sonucunda, periyodik besleme yapılmayan günlerin tetiklediği telafi büyümesinin, büyüme hızını ve yem tüketimini artırabileceği bildirilmiştir. Kim ve Lovell (1995) yine aynı türün $41 \mathrm{~g}$ ağırlığındaki bireyleriyle yaptıkları çalışmada dört farklı deneme grubu oluşturmuşlar ve telafi büyümesi gruplarını dört günde bir kez yemlemişlerdir. 18 hafta süren denemede FF grubu kontrol olarak her gün, 3W grubu ilk üç hafta boyunca telafi rejimiyle, $6 \mathrm{~W}$ grubu ilk altı hafta 
boyunca telafi rejimiyle ve $9 \mathrm{~W}$ grubu ise ilk dokuz hafta boyunca telafi rejimiyle beslenmişlerdir. Deneme bitiminde grupların son ağırlıkları FF, 3W, 6W ve 9W grupları için sırasıyla $560,570,510$ ve $495 \mathrm{~g}$ olarak kaydedilmiştir. Yine bu çalışmada da büyüme performansı bakımından telafi gruplarının kontrol grubunu yakaladığı ve hatta bir grubun geçtiği tespit edilmiştir.

Akvaryum balıklarında maliyet analizlerini araştıran bazı çalışmalar yürütülmüştür. Fujimoto vd. (2016) melek balıkların ( $P$. scalare) haftada beş gün ve haftanın her günü beslemişlerdir. Yaptıkları maliyet analizleri sonucunda ise haftada her gün beslemenin büyüme parametrelerine bağlı olarak daha karlı olduğunu ortaya koymuşlardır. Silva vd. (2007) paku (Colossoma maropomum) balıklarıyla yaptıkları besleme döngüsü çalışmasında büyüme ve maliyet üzerine olan etkileri incelemişlerdir. Balıkları her gün iki ve üç öğün, vücut ağırlıklarının \%5 ve \%10'u oranında besledikten sonra, en iyi büyümeyi üç öğün $\% 10$ oranıyla beslenen grupta bulmuşlardır. Fakat bu grubun 2 öğün beslenenlere oranla daha maliyetli olduğunu bildirmişlerdir. Ancak, büyüme performansı ve maliyet analizi parametrelerini birlikte değerlendirerek, iki öğün beslemenin daha uygun olduğu sonucuna varmışlardır. Yapılan bu çalışmada ise lepistesler için ideal bulunan besleme döngüsü maliyet açısından da daha karlı bulunmuştur.

Sonuç olarak, akvaryum balıkları üretiminde önemli kriterlerden biri de iyi bir besleme yönetiminin uygulanmasıdır.

\section{KAYNAKÇA}

Aral, O. \& Şahin, D. (2015). Sperm storage and sperm reserve usage in female guppy (Poecilia reticulata). Journal of Academic Documents for Fisheries and Aquaculture, 1:161-164.

Auer, S.K., Arendt, J.D., Chandramouli, R. \& Reznick, D.N. (2010). Juvenile compensatory growth has negative consequences for reproduction in Trinidadian guppies (Poecilia reticulata). Ecology Letters, 13:998-1007. doi: 10.1111/j.1461-0248.2010.01491.x

Chatakondi, N.G. \& Yant, R.D. (2001). Application of compensatory growth to enhance production in channel catfish Ictalurus punctatus. Journal of the World Aquaculture Society, 32(3):278-285. doi: 10.1111/j.1749-7345.2001.tb00451.x

Çelik, I., Çelik, P. \& Şahin, T. (2014). The current situation of the aquarium sector, problems and suggestions for solutions (in Turkish). In: Proceedings of I. National Aquarium Fisheries and Issues Workshop Emre, Y., Türkmen, G. (Eds.), 30-31 October 2014, Antalya, Turkey, pp. 11-19.

FAO. (2017). Food and Agriculture Organization Statistics <faostat.fao.org>, (Access Date: 25.07.2017).

Fujimoto, R.Y., Santos, R.F.B., Dias, H.M., Ramos, F.M., Silva, D.J.F. \& Honorato, C.A. (2016). Feeding frequency on the production viability of production and quantitative descriptors of parasitism in angelfish. Ciência Rural, 46(2):304-309. doi: 10.1590/0103-8478cr20141704

Harpaz, S., Slosman, T. \& Segev, R. (2005). Effect of feeding guppy fish fry (Poecilia reticulata) diets in the form of powder versus flakes. Aquaculture Research, 36(10):996-1000. doi: 10.1111/j.1365-2109.2005.01308.x

Hill, J.E. \& Yanong, R.P.E. (2010). Freshwater ornamental fish commonly cultured in Florida. University of Florida IFAS Extension, Circular 54, 5 p.
Balıkların aşırı yemlenmesi su parametrelerini olumsuz olarak etkilemekte ve ölümlere sebep olmaktadır. Ayrıca doyan balığın yem almaya devam etmesi de mortaliteye kadar varan birçok olumsuzluğu beraberinde getirmektedir. Balıklar az yemlendiğinde ise çeşitli fiziksel deformasyonlar, büyüme performansında ve üreme verimliliğinde düşüşler, kanibalizm ve tüm bunların sonunda yine ölümler meydana gelmektedir. Özellikle lepistes gibi kolay üretimi yapılan balıklar genellikle "yemle-unut" mantığıyla beslendiklerinden dolayı, balıkların üretim miktarları ve değerlerinde kayıplar yaşanmaktadır. Bu çalışmada da görüldüğü üzere lepisteslerin aç bırakılmaları, dişilerde özellikle üreme performansının düşmesine, erkeklerde ise büyümenin sınırlanmasına sebep olmuştur. Fakat her gün beslenen balıklarda bu parametrelerin ciddi olarak artıı̆ı ve maliyet açısından da pozitif sonuçlar meydana geldiği görülmüştür. Dolayısıyla hem ticari işletmelerde hem de ev akvaryumlarında bakılan lepisteslerin en azından günde bir kere beslenmeleri önerilmektedir.

\section{TEŞEKKÜR}

Bu çalışmanın bir kısmı, 1-4 Eylül 2015 tarihleri arasında Ege Üniversitesi Su Ürünleri Fakültesi tarafından İzmir'de düzenlenen 18. Ulusal Su Ürünleri Sempozyumu'nda sözlü bildiri olarak sunulmuştur. Yazarlar olarak, balıkların beslenmesi konusundaki yardımlarından ötürü Seval Kartal'a teşekkür ederiz.

James, R. \& Sampath, K. (2003). Effects of meal frequency on growth and reproduction in the ornamental red swordtail, Xiphophorus helleri. The Israeli Journal of Aquaculture-Bamidgeh, 55(3):197-207.

James, R. \& Sampath, K. (2004). Effect of feeding frequency on growth and fecundity in an ornamental fish, Betta splendens (Regan). The Israeli Journal of Aquaculture-Bamidgeh, 56(2):138-147.

Jiwyam, W. (2010). Growth and compensatory growth of juvenile Pangasius bocourti Sauvage, 1880 relative to ration. Aquaculture, 306:393-397. doi: 10.1016/j.aquaculture.2010.05.005

Karadal, O. \& Güroy, D. (2015). Effect of albinism on reproductive performance on cichlid fish: Example of powder blue and snow white (Pseudotropheus socolofi) cichlids (in Turkish with English abstract). Ege Journal of Fisheries and Aquatic Sciences, 32(3):159-163. doi: 10.12714/egejfas.2015.32.3.06

Karadal, O., Güroy, D. \& Türkmen, G. (2017). Effects of feeding frequency and Spirulina on growth performance, skin coloration and seed production on kenyi cichlids (Maylandia lombardoi). Aquaculture International, 25(1):121-134. doi: 10.1007/s10499-016-0017-x

Kasiri, M., Farahi, A. \& Sudagar, M. (2011). Effects of feeding frequency on growth performance and survival rate of angel fish, Pterophyllum scalare (Perciformes: Cichlidae). Veterinary Research Forum, 2(2):97-102.

Kim, M.K. \& Lovell, R.T. (1995). Effect of restricted feeding regimens on compensatory weight gain and body tissue changes in channel catfish Ictalurus punctatus in ponds. Aquaculture, 135:285-293 doi: 10.1016/0044-8486(95)01027-0

Krause, E.T. \& Liesenjohann, T. (2012). Predation pressure and food abundance during early life alter risk-taking behaviour and growth of guppies (Poecilia reticulata). Behaviour, 149(1):1-14. doi: 10.1163/156853912X623748 
Martínez-Llorens, S., Vidal, A.T., Moñino, A.V., Torres, M.P. \& Cerdá, M.J. (2007). Effects of dietary soybean oil concentration on growth, nutrient utilization and muscle fatty acid composition of gilthead sea bream (Sparus aurata L.). Aquaculture Research, 38(1):76-81. doi: 10.1111/j.1365-2109.2006.01636.x

Meffe, G.K. \& Vrijenhoek, R.C. (1981). Starvation stress and intraovarian cannibalism in livebearers (Atheriniformes: Poeciliidae). Copeia, 1981(3):702-705. doi: 10.2307/1444578

Montajami, S., Vajargah, M.F., Hajiahmadyan, M., Zarandeh, A.S.H., Mirzaie F.S. \& Hosseini, S.A. (2012). Assessment of the effects of feeding frequency on growth performance and survival rate of Texas cichlid larvae (Herichthys cyanoguttatus). Journal of Fisheries International, 7(2):51-54

Okorie, O.E., Bae, J.Y., Kim, K.W., Son, M.H., Kim, J.W. \& Bai, S.C. (2013) Optimum feeding rates in juvenile olive flounder, Paralichthys olivaceus, at the optimum rearing temperature. Aquaculture Nutirition, 19:267-277. doi: 10.1111/j.1365-2095.2012.00956.x

Rohul Amin, A.K.M., Bapary, M.A.J., Islam, M.S., Shahjahan, M. \& Hossain M.A.R. (2005). The impacts of compensatory growth on food intake growth rate and efficiency of feed utilization in Thai pangas (Pangasius hypophthalmus). Pakistan Journal of Biological Sciences, 8(5):766-770. doi: $10.3923 / p j b s .2005 .766 .770$

Royle, N.J., Metcalfe, N.B. \& Lindström, J. (2006). Sexual selection, growth compensation and fast-start swimming performance in Green Swordtails, Xiphophorus helleri. Functional Ecology, 20:662-669. doi: 10.1111/j.1365-2435.2006.01147.x

Silva, C.R., Gomes, L.C. \& Brandão, F.R. (2007). Effect of feeding rate and frequency on tambaqui (Colossoma macropomum) growth, production and feeding costs during the first growth phase in cages. Aquaculture, 264(1):135-139. doi: 10.1016/j.aquaculture.2006.12.007

Talbot, C., Corneillie, S. \& Korsøen, Ø. (1999). Pattern of feed intake in four species of fish under commercial farming conditions: implications for feeding management. Aquaculture Research, 30(7):509-518. doi: 10.1046/j.1365-2109.1999.00369.x

Türkmen, G. \& Alpbaz, A. (2001). Studies on aquarium fish imported to Turkey and the results (in Turkish with English abstract). Ege Journal Fisheries and Aquatic Sciences, 18(3-4):483-493.

Türkmen, G., Bulguroğlu, S.Y. \& Aydoğan, G. (2011). Bring in some native osteichtyes marine fish species in Turkey to the marine aquarium (in Turkish with English abstract). Ege Journal Fisheries and Aquatic Sciences, 28(3):95-98.

Woynarovich, A., Hoitsy, G. \& Moth-Poulsen, T. (2011). Small-scale rainbow trout farming, FAO Fisheries and Aquaculture Technical Paper, No. 561, Rome, Italy, $81 \mathrm{p}$.

Yiğit, M. \& Çelikkol, B. (2011). Feeding strategy in aquaculture (in Turkish with English abstract). Sümder Su Ürünleri Dergisi, 43/48:39-45.

Zar, J.H. (2001). Biostatistical analysis, 4th edn, Prentice Hall Inc., Upper Saddle River, New Jersey, USA, $663 \mathrm{p}$.

Zhu, X., Xie, S., Zou, Z., Lei, W., Cui, Y., Yang, Y. \& Wootton, R.J. (2004). Compensatory growth and food consumption in gibel carp, Carassius auratus gibelio, and Chinese longsnout catfish, Leiocassis longirostris, experiencing cycles of feed deprivation and re-feeding. Aquaculture, 241:235-247. doi: 10.1016/j.aquaculture.2004.07.027 